\title{
Aristóteles y la lluvia, una vez más
}

\author{
GABRIELA RossI \\ Consejo Nacional de Investigaciones Científicas y Tecnológicas \\ CONICET \\ rossigabriela@gmail.com
}

\begin{abstract}
Resumen: El texto de Física II 8 ha constituido recientemente ocasión para rehabilitar la tesis según la cual Aristóteles sostendría la vigencia de una teleología natural externa, e incluso antropocéntrica, sobre todo a partir del trabajo de D. Furley y especialmente de D. Sedley. En este trabajo ofrezco una serie de argumentos en contra de esta interpretación del texto de la Física. De este modo, defenderé la lectura según la cual Aristóteles no sostiene, en este capítulo, que llueve con vistas al crecimiento del grano, en contra de lo que hoy constituye una opinión un tanto extendida.
\end{abstract}

Palabras clave: Física II 8, teleología inmanente, teleología externa, antropocentrismo

\begin{abstract}
The text of Physics 2.8 has been recently interpreted so as to restore the reading that Aristotle holds an external, and even an anthropocentric, natural teleology. This reading has been defended by D. Furley, and especially by D. Sedley. In this paper I present several arguments against this interpretation of the text. Thus, I will argue that Aristotle does not claim, in this chapter, that it rains for the sake of the growing of the crop, against an opinion which is currently somewhat extended among interpreters.
\end{abstract}

Key words: Physics 2.8, immanent teleology, external teleology, anthropocentrism

En Física (Fís.) II 8 Aristóteles hace algunas afirmaciones que recientemente han constituido ocasión para rehabilitar la tesis según la cual este filósofo sostendría la vigencia de cierto tipo de teleología natural interactiva o de segundo orden. ${ }^{1}$ Se trata de lecturas formuladas por algunos autores provenientes de la tradición interpretativa anglosajona, según las cuales Aristóteles sostendría que llueve con vistas al crecimiento del grano sembrado, en el marco de su primera línea de argumentación dirigida a defender la tesis de que la naturaleza es una causa como "aquello con vistas a lo cual" en Fís. II 8. Esta afirmación acerca del "fin" de la lluvia, en caso de ser atribuible a Aristóteles, constituye una de las bases sobre las que se apoya la interpretación según la cual

${ }^{1}$ Me refiero fundamentalmente a D. Furley (1985) y D. Sedley (1991), que son quienes defienden explícitamente con más fuerza y más eco este tipo de interpretación, cuyos antecedentes son señalados por el propio Sedley en 1991, p. 179, n. 2.

Diánoia, volumen LV, número 65 (Noviembre 2010): pp. 91-123. 
podría identificarse una teleología no sólo "inmanente" a cada sustancia natural, sino incluso una "de segundo orden", "externa", "interactiva", "global" o "universal", tal que los diferentes fines correspondientes a cada sustancia se ordenarían jerárquicamente, de donde resultaría que el fin de una sustancia o un proceso podría ser el beneficio de otra sustancia "superior" en la jerarquía natural. ${ }^{2}$

El problema relativo a la existencia de algún tipo de finalidad de segundo orden en Aristóteles, i.e., una que operase "por encima" de la finalidad inmanente a cada una de las sustancias naturales, es una cuestión de largo alcance alrededor de la cual existe una amplia controversia. ${ }^{3}$ Incluso se discute, en torno a este problema, qué tipo de finalidad "extrínseca" a los entes naturales sería plausible atribuir, si acaso, a Aristóteles. Hay en este punto una amplia gama de matices que van desde la mera constatación de un orden intersustancial (el cual puede verificarse sin necesidad de adscribir al mismo un papel estrictamente causal respecto de las sustancias particulares y de las especies que lo integran), hasta una concepción finalista cosmológica vertical o de tipo teocéntrico, al modo del aristotelismo medieval, ${ }^{4}$ pasando por concepciones cosmológicas de tipo antropocéntrico, al modo de Jenofonte ${ }^{5} \mathrm{o}$, posteriormente, de Crisipo. ${ }^{6}$

En los años sesenta del siglo pasado, W. Wieland había sido uno de los primeros autores en ofrecer argumentos de peso contra la idea de que Aristóteles pudiera haber postulado un principio teleológico de tipo cosmológico (Wieland 1970, pp. 255-259) y enfrentarse a interpre-

${ }^{2}$ Los otros textos en que se apoya usualmente una lectura tal de la teleología aristotélica son Política I 8, 1256b10-22 y Metafísica $\Lambda$ 10, 1075a11-25. Discutiré este último texto un poco más adelante. Para una buena discusión del pasaje de Política I 8 puede verse Judson 2005, pp. 356-358, y especialmente Scharle 2008, pp. 161-165.

${ }^{3}$ Para una informativa historia de la recepción de la teleología aristotélica que refleja los orígenes históricos de las partes en esta vexata quaestio, véase Johnson 2005, pp. 15-39.

${ }^{4}$ No deja de ser digno de mención, con todo, el hecho de que Tomás de Aquino entienda que precisamente en Fís. II 8 Aristóteles sostiene que no llueve con un propósito o con vistas a algo (In octo libros Physicorum, 2, 12, 3).

${ }^{5}$ Memorabilia, IV 3.

${ }^{6}$ Cfr. Cicerón, De Natura Deorum I 39 (LS 54B, SVF II 1077), ibid. II 14, 37 (SVF II 1153), ibid. II 37-39 (LS 54H), y esp. ibid. II 133 (LS 54N), De finibus bonorum et malorum III 67 (LS 57F, esp. 25-29), Porfirio, De Abstinentia III 20 (LS 54P, SVF II 1152), Gelio, Noctes Atticae VII 1 (LS 54Q, SVF II 1169-1170), Lactancio, De ira dei 13, 9-10 (LS 54R, SVF II 1152). Las siglas empleadas remiten a las siguientes obras: LS a Long y Sedley 1987, SVF a Arnim 1903-1905, DK a Diels y Kranz 1951, y LSJ a Liddell, Scott y Jones 1996.

Diánoia, vol. LV, no. 65 (Noviembre 2010). 
taciones en ese momento tradicionales, como las de E. Zeller (1921, pp. 330 ss. y 427 ss.) y A. Mansion (1946), quienes, sin dejar de reconocer el carácter inmanente de la 甲úoıs como causa final, sostenían al mismo tiempo la existencia de una finalidad externa a las sustancias como una suerte de principio cosmológico. Desde el ámbito de los estudios específicos acerca de la biología aristotélica, y ya en los años setenta y ochenta del mismo siglo, A. Gotthelf (1987) argumenta en pos de una interpretación fuertemente inmanentista de la teleología aristotélica, y M. Nussbaum (1978, pp. 59-106, esp. las pp. 60, 93-97), W. Kullmann (1985, p. 174), y D. Balme (1987a; 1992, pp. 93-98) sostienen la vigencia exclusiva de la teleología inmanente a las sustancias naturales y descartan la presencia en Aristóteles de una finalidad externa o de segundo orden, una "consecuencia horrenda" para cualquier interpretación, según el vehemente diagnóstico de D. Balme (1987b, p. 299).

Probablemente en gran medida a raíz de estos desarrollos, hacia fines de los ochenta E. Berti, sin dejar de reconocer que Aristóteles admite la existencia del orden intersustancial en el plano sublunar, diagnosticaba que las lecturas teocéntricas y antropocéntricas de la teleología aristotélica ya no constituyen opciones lo suficientemente serias como para ser objeto de discusión exegética, sino que el problema pendiente es más bien el de la relación entre la teleología metafísica y la física (sc. la relación entre el primer motor inmóvil como causa final y la finalidad natural inmanente). ${ }^{7}$ No obstante, lo cierto es que de hecho ya se había postulado nuevamente la idea de una teleología "externa" en Aristóteles (Cooper 1982, pp. 217-221), y, más aún, algunos prestigiosos autores provenientes de otras tradiciones interpretativas logran, alrededor de estas mismas épocas, reinstalar la discusión acerca de una interpretación de la teleología aristotélica de corte cosmológico, como es el caso de D. Furley (1985), o incluso abiertamente antropocéntrico, como ha propuesto D. Sedley en un polémico artículo publicado a comienzos de los años noventa.

Tal como algunos autores que han tomado parte en este debate ( $c f r$. Wardy 1993), considero que la cuestión relativa al problema de la vi-

${ }^{7}$ Berti 1989-1990. Por su parte, en una monografía reciente acerca de la teleología aristotélica, M. Johnson ha vuelto ha rechazar enfáticamente la posibilidad de una teleología externa en todas sus versiones (especialmente la antropocéntrica), con menos matices, por cierto, que Berti; aunque no por ello deja de reconocer que existe algún tipo de orden o acuerdo intersustancial en la naturaleza, un orden que no respondería, según Johnson, a una causa final externa a las sustancias mismas (Johnson 2005, p. 283).

Diánoia, vol. LV, no. 65 (Noviembre 2010). 
gencia de una teleología de segundo orden en Aristóteles tiene mucho de aporética, no sólo a partir de las dificultades interpretativas que ofrecen los textos en los cuales habría de decidirse esta cuestión, sino además y fundamentalmente desde el punto de vista sistemático. En efecto, si bien tiendo a creer que no es plausible adjudicar a Aristóteles una concepción teleológica natural de segundo orden, al mismo tiempo creo que hay que admitir que resulta difícil negar que existe el reconocimiento de algún tipo de orden intersustancial en la concepción de la naturaleza de este filósofo. ${ }^{8}$ Cuál sea la causa, si es que la hay, del acuerdo intersustancial en el plano sublunar, resulta, a mi entender, poco claro a partir de los textos. ${ }^{9}$ La aporía a que nos remite el problema puede reconstruirse del siguiente modo: si el orden intersustancial es el resultado del hecho de que cada sustancia realice su fin inmanente, entonces no hay causa final del mencionado acuerdo intersustancial en cuanto tal, sino de cada una de sus partes, lo cual es tanto como decir que dicho orden es en definitiva -y en el sentido propiamente aristotélico del término-azaroso. Por el contrario, si optamos por afirmar que el orden es causado por una causa final, entonces habría que conceder que la misma operaría por encima de los fines intrínsecos de cada una de las sustancias, los cuales se subordinarían a ella, lo que parece a primera vista tan implausible como lo anterior.

Mi propósito en este texto, con todo, es mucho más modesto que el de intentar dar una respuesta a este asunto aporético de amplio alcance. Intentaré meramente comenzar a despejar algunas de las cuestiones concernientes a la base textual en la cual se apoya el renacido debate (o buena parte de él). Concretamente, me propongo ofrecer una serie de argumentos que abonarían la tesis según la cual Fís. II 8, al menos, no es uno de los textos en los que pueda apoyarse una interpretación "externa" de la teleología aristotélica, del tipo propuesto por autores como D. Furley o D. Sedley. De este modo, defenderé la lectura hasta hace poco tradicional, según la cual Aristóteles no sostiene, en este

${ }^{8}$ Cfr., por ejemplo, Metafísica $\Lambda$ 10, 1075a16-18.

${ }^{9}$ Berti 1989-1990 afirma que no resulta en absoluto claro que ese orden sea causado de forma directa por el primer motor inmóvil como una causa final que esté por encima de las sustancias, es decir, una causa final como un bien superior al cual se subordinara directamente el bien propio de cada sustancia. Según reconstruye este mismo autor, este orden resultaría 1) del hecho de que cada cosa tiende a su fin propio o inmanente, 2) del papel del motor inmóvil como causa final externa del cielo, siendo que este último tiene también, a su vez, una causa final interna; pero no resulta aún del todo claro, como puede verse, de qué modo esto produce o causa el orden intersustancial sublunar.

Diánoia, vol. LV, no. 65 (Noviembre 2010). 
capítulo, que llueve con vistas al crecimiento del grano, en contra de lo que hoy constituye una opinión un tanto extendida. ${ }^{10}$

Si estoy en lo cierto, esto además restaría un apoyo fundamental a la interpretación según la cual Aristóteles sostiene una teleología natural de segundo orden, en cuanto el texto en discusión constituye el único pasaje físico de Aristóteles en el cual habría alguna oportunidad de encontrar la postulación de este tipo de teleología, y además se encontraría, nada menos, en el libro en que nuestro filósofo establece los principios y causas de la física como ciencia, es decir, en un texto fundacional de la filosofía de la naturaleza aristotélica. Dado que las lecturas que entienden que en este pasaje Aristóteles afirma que llueve con vistas al crecimiento del grano defienden la universalidad de la teleología natural, o bien, que la naturaleza exhibe una teleología antropocéntrica al modo estoico, en tal medida resulta para ellas especialmente importante encontrar apoyo en este pasaje de la Fís. Es el caso de D. Furley, quien centra toda su discusión en este capítulo de la Fís., y de D. Sedley, quien le otorga expresamente a la discusión de este texto un lugar central en su artículo.

\section{II}

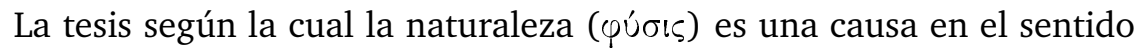
de "aquello con vistas a lo cual" o "el fin" se postula en las dos líneas iniciales de Fís. II 8 como aquello que ha de ser probado (198b1011) y es reafirmada en las dos líneas finales, como aquello que se ha logrado probar (199b32-33). ${ }^{11}$ A lo largo del capítulo encontramos

${ }^{10}$ Las excepciones, hasta donde conozco, son R. Wardy (1993), y más recientemente M. Johnson (2005), L. Judson (2005) y M. Scharle (2008).

${ }^{11}$ Vale aclarar con todo que, como enfatiza Johnson (2005), Aristóteles - del mismo modo que luego Teofrasto en su Metafísica- no defiende la tesis según la cual todo lo que ocurre en la naturaleza sublunar, e incluso en los cielos, está orientado con vistas a un fin: el eclipse, por mencionar un ejemplo conspicuo, no lo está (Met. H 4, 1044b12), y es —al menos- objeto de debate que la lluvia lo esté. En efecto, Aristóteles admite que algunas cosas y procesos naturales se deben meramente a la necesidad. Según algunos intérpretes en esta categoría estarían los fenómenos meteorológicos (cfr. Johnson 2005, pp. 149-158; contra Cooper 1982, pp. 217-218, con n. 12; Broadie 1982, pp. 79-80; Furley 1985; Sedley 1991, y Matthen 2001); pero ni siquiera todas las partes de los seres animados podrían ser explicadas por recurso directo a la causa final; $v . g r .$, los residuos ( $\pi \varepsilon \rho \iota \tau \omega \omega \mu \alpha \tau \alpha)$ producidos por la actividad de ciertos órganos tienen por causa la necesidad material y no son con vistas a algo (Sobre las partes de los animales, IV 2, 677a1314, cfr. ibidem. III 7, 670a29-31, III 14, 674a17-18, 675b36; Sobre la generación

Diánoia, vol. LV, no. 65 (Noviembre 2010). 
tres grandes líneas de argumentación dirigidas a defender dicha tesis, que había sido introducida por vez primera en el capítulo 2 del mismo libro (194a27-29). ${ }^{12}$ Nos ocuparemos aquí de la primera argumentación.

La tesis central del capítulo se plantea desde el comienzo como contrapuesta a la tesis — atribuida a Empédocles- según la cual el modo en que los animales se generan, y la constitución de los animales a partir de sus partes, ocurren por azar. Esta última tesis se menciona inicialmente en el marco de una posible objeción o dificultad ( $\alpha \pi \circ \rho^{\prime} \alpha$ ) y es en este contexto donde Aristóteles introduce las afirmaciones controvertidas acerca de la supuesta finalidad de la lluvia. Citaré in extenso el texto en cuestión para poder analizarlo luego con detenimiento.

Y existe la siguiente dificultad [åmopía], a saber: (I) qué impide que la naturaleza no haga $\langle$ las cosas〉 con vistas a algo, ni porque es mejor, sino

de los animales I 15, 724b26-27, etc.; Cooper 1987; cfr. Johnson 2005, pp. 186, 197). Algunos intérpretes sostienen, además, de modo más general, que la finalidad está ausente en los procesos que involucran entes inanimados (cfr. Charlton 1992, p. 120; Nussbaum 1978, pp. 59-99), restringiendo así el ámbito de la teleología a los procesos que involucran seres vivos, lo cual — de ser correcto- permitiría encuadrar la teleología de Aristóteles dentro de las mismas coordenadas bajo las cuales las explicaciones teleológicas resultan aceptables hoy día; i.e., especialmente en la biología (véase Mayr 1992, p. 125). Por cierto, con respecto a esto último, no hay un acuerdo generalizado entre los intérpretes de Aristóteles; la mayoría de ellos, de hecho, tiende a creer que los movimientos de los cuerpos simples son con vistas a un fin a pesar de que ellos son inanimados - para un punto de vista diferente, véase Gotthelf 1987, p. 214 n. 19-. Puede verse un resumen de la discusión alrededor de este último problema en Johnson (2005, pp. 140 ss.), quien, si bien admite que el comportamiento de los elementos sería explicado teleológicamente, señala que la vigencia de la teleología resulta más convincente en el nivel de complejidad correspondiente a los organismos y no tanto a nivel de los cuerpos simples (Johnson 2005, p. 288).

${ }^{12}$ La primera argumentación comienza con el planteamiento de una dificultad o aporía (198b16-199a8; cfr. 199b13-26). La segunda línea de argumentación, dentro de la cual se pueden reconstruir a su vez varios argumentos (199a8-20;

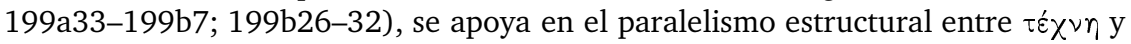
Qúoıs para inferir el carácter teleológico de la segunda a partir de diversas características de la primera. La tercera línea argumentativa, señalada por Aristóteles como la más fuerte (199a20), apela a los procesos observables en la naturaleza viviente, más precisamente en los animales y plantas que claramente no actúan ni por técnica ni por deliberación, pero que sin embargo realizan actividades o exhiben procesos orientados a un fin, v.gr. su conservación (199a20-32; cfr. 199b9-13).

Diánoia, vol. LV, no. 65 (Noviembre 2010). 
(a) tal como Zeus llueve; ${ }^{13}$ i.e., no para que crezca el grano, sino por necesidad (pues es necesario que lo que se ha elevado se enfríe, y habiéndose enfriado, al convertirse en agua (es necesario〉 que caiga; en cambio, acae-

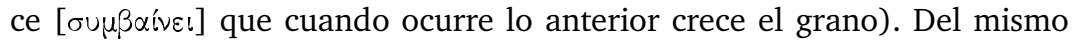
modo, si el grano se le arruina a uno en el sembradío, no llueve con vistas a esto; $v$.gr., para que se arruine $\langle$ el grano〉, sino que ello acaeció. De modo que (b) ¿qué impide que, en la naturaleza, ocurra de este mismo modo con las partes de los seres vivos? Por ejemplo, ¿〈qué impide $\rangle$ que los dientes 〈incisivos〉 crezcan por necesidad en la parte delantera y sean filosos y aptos para cortar, mientras que las muelas en cambio sean planas y aptas para triturar el alimento, cuando no se generan $\langle$ así $\rangle$ con vistas a esto [sc. con vistas a cumplir esa función], sino que ello resulta una mera coincidencia? Y de modo semejante ocurre en lo que respecta a las demás partes de los animales, en las cuales parece darse lo "con vistas a algo". (c) En resumen: allí donde todas las cosas resultan tal como si se hubieran generado con

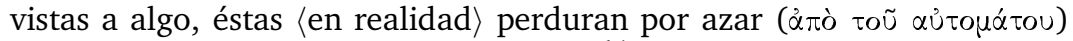
al estar constituidas de modo favorable; ${ }^{14}$ en cambio, las que no 〈están constituidas $\rangle$ de este modo, perecieron y perecen, tal como afirma Empédocles acerca de los bueyes con rostro de hombre. Pues bien, el argumento a raíz del cual uno podría encontrarse en dificultades es éste, u otro de este tipo, si es que lo hay.

(II) Pero es imposible que sea de ese modo, pues (i) estas $\operatorname{cosas}^{15} \mathrm{y}$ todas las que son por naturaleza se generan siempre, o la mayoría de las veces, del mismo modo, mientras que ello no ocurre con ninguna de las que son por fortuna o por espontaneidad. (ii) En efecto, no parece que sea por fortuna ni por coincidencia que llueva con frecuencia en invierno, sino 〈que parece ser por azar〉 cuando ello sucede en verano. Y tampoco 〈parece ser por azar〉 que haga calor en verano, sino 〈que parece serlo〉 cuando ocurre en invierno. (iii) Por tanto, como parece que 〈estas cosas son o bien por coincidencia o bien con vistas a algo, y si no es posible que ellas sean ni por coincidencia ni por espontaneidad, entonces serán con vistas a algo. Pero todas estas cosas son ciertamente por naturaleza, tal

${ }^{13}$ El verbo "llover" ( $(\omega)$ es usado por Homero de modo personal, tal que Zeus es el sujeto que realiza la acción de llover (Ilíada XII.25; Odisea XIV.457), después de Homero ư $\omega$ comienza a ser usado también de modo impersonal (cfr. LSJ s.v.). D. Sedley (1991, pp. 185-186) toma la utilización de esta expresión por parte de Aristóteles como un signo de que nuestro filósofo está aquí pensando en una teleología con rasgos antropocéntricos. R. Wardy (1993, p. 20) considera que esto es una exageración de Sedley, y por mi parte coincido en que es, por lo menos, una sobreinterpretación.

${ }^{14}$ Esto es: favorable para la supervivencia y probablemente para la reproducción.

${ }^{15} \mathrm{El}$ antecedente del $\tau \alpha \tilde{\tau} \tau \alpha$ no es inmediatamente claro, pero a mi juicio todo indica que se trata de los seres vivos (con sus partes), es decir, aquello que ha mencionado en último término en el argumento anterior, y que está en discusión precisamente; lo mismo opinan D. Furley (1985) y L. Judson (2005).

Diánoia, vol. LV, no. 65 (Noviembre 2010). 
como afirmarían incluso los mismos que sostienen estas cosas [sc., los que sostienen argumentos del tipo mencionado]. Por lo tanto, lo "con vistas a algo" se da en las cosas que son y se generan por naturaleza. (198b16199a8) ${ }^{16}$

En las siguientes secciones analizaré ambas partes del pasaje citado. El análisis de la dificultad o aporía (I) de 198b16-32 ocupará las secciones III-IV de este artículo, mientras que el análisis del contraargumento (II) de 198b32-199a5 ocupará la sección V, donde intentaré explicar cuál es la función que, según entiendo, cumple el ejemplo de la lluvia en invierno y el calor en verano en la argumentación contra la tesis materialista.

\section{III}

Creo que para los fines del análisis del pasaje es conveniente hacer un par de observaciones generales respecto del contexto argumentativo, comenzando por el sentido de la aporía (I). En primer lugar, hay que tener en cuenta que se trata aquí de una dificultad o aporía, tal como Aristóteles la presenta desde un comienzo y repite al final del pasaje. Esta dificultad concierne a la tesis según la cual la naturaleza es una causa final. La aporía no parece haber sido formulada por los materialistas, sino por el propio Aristóteles en una versión probablemente algo estilizada. ${ }^{17}$

${ }^{16}$ La traducción de los textos es mía, excepto cuando se indica lo contrario.

${ }^{17}$ Para una opinión diferente, véase Furley 1985. La razón fundamental por la que me inclino a considerar que la aporía habría sido formulada por el propio Aristóteles es que la contraposición entre materialismo y teleología, tal como aparece formulada en la aporía, sólo puede establecerse desde el punto de vista de una concepción teleológica como la de Aristóteles, en la medida en que constituye una dificultad para esta concepción teleológica, precisamente. En otras palabras, la aporía presupone la teleología aristotélica. Para este punto puede verse, además, Hirsch 1990, quien muestra que ni siquiera los atomistas habrían tenido a la vista una concepción teleológica tan diferenciada a la cual oponerse. A esto se pueden agregar las impresiones de Sedley 1991 (con quien estoy de acuerdo en este punto), quien también señala algo importante: la explicación del proceso de la lluvia por causas mecánicas, que hallamos en la aporía, es aristotélica, ya que coincide con la que nuestro filósofo ofrece, por ejemplo, en Meteorológicos I 9, 346b23-31 (texto citado más abajo) y Sobre el sueño y la vigilia 457b31-458a1. Dicha explicación, en efecto, presupone concepciones aristotélicas sobre los cuerpos elementales, sus lugares propios y su transformación mutua, así como el papel causal del sol en estas transformaciones, lo cual agrega elementos para pensar que la formulación de la aporía corre por cuenta de Aristóteles. En este sentido parece inclinarse también

Diánoia, vol. LV, no. 65 (Noviembre 2010). 
El argumento presentado pretende establecer una analogía entre la estructura de dos fenómenos: partiendo de un caso $(a)$, se infiere que la misma configuración causal que se da en este caso, se da en un segundo caso (b) aparentemente similar al primero; a partir de lo cual se concluye $(c)$, en general, que las generaciones de las partes de los animales no ocurren con vistas a algo (sc. a la forma o esencia del ser vivo), sino por azar. El tipo de concepciones a las que Aristóteles se refiere aquí sostendría, pues, que la coincidencia de determinadas partes (las cuales poseen a su vez determinadas características) en un ser vivo no es causada por la esencia del ser vivo, ni por el beneficio que dichas partes comportarían respecto de la esencia del ser vivo en cuestión, sino que la presencia conjunta de manos de hombre y cabeza de hombre y corazón de hombre, etc., en un mismo ser vivo, es meramente accidental o azarosa. ${ }^{18}$ Esto implica, en última instancia, la negación o el desconocimiento de la forma como causa final de las partes y de la generación. En efecto, las partes del ser vivo, según entiende Aristóteles, se constituyen en una genuina unidad en el ser vivo, y no son un mero agregado producto de una coincidencia fortuita. La causa de esta unidad no accidental es, precisamente, la forma que constituye el principio del ser vivo como un todo, y con ello de cada una de sus partes. ${ }^{19} \mathrm{Y}$ ella es causa como "lo mejor", es decir, como aquello con vistas a lo cual son las partes. En este sentido, la tesis atribuida a Empédocles según la cual el azar sería responsable de las generaciones naturales resulta, en última instancia, de su desconocimiento de la forma como el sentido principal de "naturaleza" (cfr. Sobre la generación y la corrupción II 6, 333 b5 ss.; cfr. Sobre las partes de los animales I 1, 642a24-26) y ello, en

M. Boeri (1993, p. 202) y —siguiendo a W.D. Ross (1936, p. 528) — hace la sal-

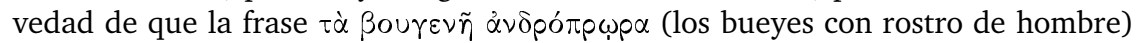
aparece en el fragmento DK61 de Empédocles, pero sólo para referirse a la generación de criaturas monstruosas.

${ }^{18}$ Cfr. Fís. II 4, 196a23-24.

${ }^{19}$ Las explicaciones materialistas de la generación de las partes de los animales, en cuanto que no consideran el beneficio de cada parte respecto del alma (sc., cierta actividad propia del ser vivo en cuestión) como causa de dichas partes, son explicaciones atomizadas. Me refiero a lo siguiente: ellas pueden explicar — prima facie - por qué la columna está compuesta por vértebras, por qué hay una cabeza con tales características, y un corazón, etc. Pero no pueden explicar la concurrencia de esa multiplicidad de partes en un ser vivo determinado: ella es meramente una coincidencia ( $c f r$. esp. el fragmento DK57 de Empédocles). Así, la teleología es en alguna medida una forma de dar cuenta causalmente de la unidad en la multiplicidad. 
definitiva, resulta en una eliminación de la naturaleza, al menos en su sentido prioritario; i.e., la forma. ${ }^{20}$

Por lo dicho, es evidente que Aristóteles considera que la aplicación de esta configuración causal a $(b)$ es falsa, pero no existe en cambio un acuerdo generalizado en la literatura especializada acerca de que él considere que $(a)$ es verdadero, ${ }^{21}$ sino que éste es precisamente uno de los puntos en discusión.

Pues bien, atendiendo a la estructura del contexto argumentativo hay que decir lo siguiente. La conclusión del argumento explica, en parte, por qué el mismo constituye una dificultad ( $\alpha \dot{\pi}$ opí $\alpha$ ): dicha conclusión es contraria a la tesis que Aristóteles pretende establecer en este capítulo. Pero esto es sólo parte de la explicación acerca de por qué este argumento comporta una dificultad, según afirma Aristóteles. En efecto, en otros lugares del corpus en que Aristóteles presenta la tesis materialista como posible explicación de los procesos naturales, de hecho, él no se refiere a ella como fuente de una dificultad, a pesar de que ella se opone siempre a su propia concepción teleológica y por lo tanto es considerada falsa. Así, no es sólo la falsedad de la conclusión de este argumento lo que determina que quien defiende una concepción teleológica de los procesos naturales esté en este caso ante una dificultad, sino además y fundamentalmente el tipo de premisas en que dicha conclusión se apoya. Más precisamente, la razón por la cual este argumento comporta una dificultad es el hecho de que su punto de partida sería - al menos- aceptable para Aristóteles y sus oyentes, mientras que la conclusión que parece seguirse, sin embargo, no lo es. ${ }^{22}$ Resulta difícil, de hecho, comprender por qué Aristóteles afirma-

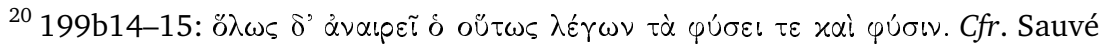
Meyer 1992. La tesis rival, según la cual no hay causa final de la generación de las diferentes partes que conforman un ser vivo, resulta, pues, de la apelación a la sola materia elemental y sus propiedades dinámicas para dar cuenta de dichas generaciones, es decir, a la naturaleza concebida meramente como $u \lambda \eta$.

${ }^{21}$ Entre quienes sostienen que según Aristóteles llueve con vistas a algo puede mencionarse, por ejemplo, a J. Cooper (1982), S. Waterlow Broadie (1982, p. 80, n. 29) y los mencionados D. Furley (1985), D. Sedley (1991), M. Matthen (2001) y J.A. Ross (2007, pp. 88-89).

${ }^{22}$ En otros textos, Aristóteles se refiere a las ảiopíaı como a la presentación de argumentos igualmente persuasivos a favor de tesis contrapuestas (Tópicos I 11, 104b12-14; VI 6, 145b16-20; cfr. Rossi 2006, pp. 101-105), lo cual parece ser el sentido más estricto de $\alpha$ ropía desde el punto de vista argumentativo. No obstante, entendiendo el término $\alpha \dot{\pi}$ opía en un sentido un tanto más laxo, i.e., simplemente como una dificultad ante la que uno se encuentra, lo dicho antes resulta válido: la presentación de una tesis que consideramos falsa no basta para ponernos en difi-

Diánoia, vol. LV, no. 65 (Noviembre 2010). 
ría encontrar dificultad alguna en un argumento cuyas premisas fueran tan abiertamente falsas, absurdas, inaceptables o implausibles, como su conclusión. Por el contrario, creo que hay que considerar la posibilidad de que, al admitir este argumento como una dificultad, Aristóteles hubiera concedido el punto de partida de este argumento, al menos, como plausible, y quizá incluso como verdadero. En cambio, podemos pensar que un argumento cuya conclusión se opone a las tesis propias, pero que resulta demasiado rudimentario, y además cuyas premisas son absurdas o abiertamente falsas, no comporta dificultad ( $\left.\dot{\alpha} \pi \circ p^{\prime} \alpha\right)$ alguna, tal como sostiene Aristóteles respecto de los argumentos de Meliso (cfr. Fís. I 2, 185a11).

Si bien estas razones de tipo general no son conclusivas, hacen que sea al menos plausible pensar que el primer término de la comparación (a) (es decir, el caso inicial) es compatible con la doctrina aristotélica, i.e., se trata de algo que Aristóteles aceptaría; mientras que el caso $(b)$ no resulta genuinamente análogo al primero, y por lo tanto la extensión del esquema causal de $(a)$ a $(b)$ es, según nuestro filósofo, ilegítimo y resulta en una conclusión falsa. De ahí la dificultad: uno estaría dispuesto a aceptar una premisa de la cual, sin embargo, se sigue algo (o parece seguirse algo) que uno no está dispuesto a aceptar, sino que considera falso.

Sobre las razones para sostener que el primer término de la comparación $(a)$ es compatible con la doctrina aristotélica, vale la pena mencionar brevemente que, como lo reconoce el propio Sedley (1991, p. 182), la explicación del proceso de la lluvia que Aristóteles ofrece allí coincide con las descripciones de este fenómeno climático que encontramos en otros textos, por ejemplo:

Pues bien, la causa motriz, principal y primera entre los principios es manifiestamente el círculo en que se da la traslación del sol, pues, disgregando o agregando en la medida en que se acerca o se aleja, es causa de la generación y la corrupción. Mientras que la tierra permanece en reposo, la humedad en torno a ella, al ser evaporada por los rayos $\langle$ del sol $\rangle$ y por el restante calor de arriba, asciende. Pero cuando el calor que la hizo ascender la abandona, en parte por ser dispersado hacia la región superior, en parte por extinguirse a causa de haberse elevado tanto hacia el aire que está por encima de la tierra, entonces el vapor se condensa de nuevo al enfriarse a causa de la pérdida del calor y de la altura, y se forma agua a

cultades, y tampoco la presentación de un argumento cuyas premisas consideramos falsas o que no estaríamos dispuestos a aceptar (en tal caso, en efecto, no habría ninguna razón que fuerce a aceptar la conclusión). 
partir del aire; y, una vez formada, cae nuevamente a la tierra. (Meteorológicos I 9, 346b20-31)

Como puede verse en este texto, al momento de estudiar específicamente los fenómenos meteorológicos, Aristóteles da una explicación de la lluvia muy similar a la que aparece en la aporía (I) de Fís. II 8, tal que sólo apela a la necesidad material para dar cuenta de la lluvia. ${ }^{23} \mathrm{Se}$ trata de un proceso circular de transformación elemental que es producido por la circunvolución solar y el calor asociado a la misma, y por el enfriamiento del aire en la región superior. En esta medida, puede decirse que Aristóteles sostendría que, en efecto, llueve por la necesidad asociada a los procesos de transformación elemental. Por cierto, estos procesos de transformación, como ya han señalado otros autores, ${ }^{24}$ podrían explicarse teleológicamente en función de la teleología elemental (me ocuparé de este asunto en la siguiente sección). El punto en discusión es, empero, si Aristóteles estaría dispuesto a sostener que, además, llueve con vistas al crecimiento del grano, una tesis de la cual no encontramos rastro en los Meteorológicos; pues, en efecto, en el pasaje citado no hay mención alguna de una finalidad extrínseca al proceso de la lluvia, tal que ella permita explicar dicho proceso o dar cuenta de él causalmente.

Si estoy en lo cierto, pues, la dificultad (I) consiste en considerar que existe la misma relación entre $(a)$ la lluvia como un proceso que ocurre por necesidad material y el beneficio (o perjuicio) que resulta de ella para el grano o para el agricultor y (b) que las partes del animal se hayan generado de un modo determinado y el beneficio que esas partes aportan al ser vivo en cuestión. Esa relación que, según este argumento materialista, sería común e idéntica en ambos casos, es accidental o azarosa. Así como no llueve con vistas a que el grano crezca o se arruine, los dientes no son de este modo con vistas a los hábitos alimenticios de este animal, sino que ello resulta meramente de aquel modo con

${ }^{23}$ Cfr. también Meteorológicos I 11, 347b11-20; Sobre el sueño y la vigilia 457b31-458a1. El caso de la lluvia es incluso usado como un típico ejemplo de necesidad material absoluta, i.e., de causación circular, en la cual son posibles las deducciones a tergo (Sobre la generación y la corrupción II 11, 338a14-b8; Analíticos posteriores II 12, 95b38-96a7), por oposición a las generaciones naturales que son "unidireccionales" y donde no rige por lo tanto ese tipo de necesidad, ni de demostraciones a tergo. Para la lluvia como un proceso circular que sigue el movimiento (circular) del sol, véase también el texto antes citado de Meteorológicos I 9, 346b20-21 con 346b35-347a3.

${ }^{24}$ Matthen 2001; Scharle 2008.

Diánoia, vol. LV, no. 65 (Noviembre 2010). 
independencia de la causa por la cual los dientes/la lluvia se producen. Acorde a un modelo explicativo de tipo materialista, entonces, la finalidad en la naturaleza resultaría meramente de una confusión en la consideración de los procesos naturales de generación, confusión según la cual lo que en realidad sería la mera concomitancia entre el resultado de un proceso y el hecho de que el mismo resulte beneficioso para cierta entidad, se entiende como una relación causal de dependencia en sentido final. Según esta postura, tal como la describe Aristóteles, los procesos naturales no estarían real e intrínsecamente causados por un fin, sino que en todo caso ellos, teniendo por causa la mera necesidad material, culminan en resultados más o menos útiles o favorables considerados desde un punto de vista que es, por así decir, externo a los procesos mismos, y por lo tanto accidental respecto del proceso considerado en sí mismo.

\section{IV}

Como he dicho, las consideraciones generales que he ofrecido en la sección anterior no son conclusivas. Entre otras cosas, se me podría objetar que el término inicial de la comparación $(a)$ es falso pero plausible, $\mathrm{y}$ por ello implica una dificultad, con lo cual, Aristóteles todavía creería verdadero (aunque implausible) que llueve con vistas a que el grano sembrado crezca.

A los argumentos que ya han dado otros intérpretes sumaré, pues, otros cinco que agregan peso en contra de la idea de que Aristóteles está defendiendo aquí una teleología natural de tipo cosmológico, o incluso antropocéntrico. ${ }^{25}$ Estos argumentos abonarían en cambio a la idea de que Aristóteles no sostiene en este texto que llueve con vistas al crecimiento del grano, ni del grano sembrado, o al menos no en un sentido causalmente relevante, si se entiende por tal el tipo de causa que constituye la qúors tal como es entendida en el contexto de Fís. II respecto de los procesos naturales.

1. Mi primer argumento se refiere al contexto temático en que encontramos la dificultad (I). La discusión acerca de la naturaleza llevada a cabo a lo largo de todo el libro II conduce a inclinarse en contra de la idea de que Aristóteles pudiera defender aquí la vigencia de una teleología interactiva o de segundo orden, en cuanto que en el contexto

${ }^{25}$ Cfr. Wardy 1993, y ahora Judson 2005, Johnson 2005, pp. 149-157; Scharle 2008. Johansen (2006) ha criticado, a su vez, los argumentos de Johnson contra Sedley.

Diánoia, vol. LV, no. 65 (Noviembre 2010). 
global de este libro nuestro filósofo apunta a defender y desarrollar la idea de que la naturaleza es un principio interno del movimiento de las entidades en las cuales se encuentra (192b13-33); i.e., se trata en cada caso de la naturaleza de una entidad particular; y esto al punto tal que

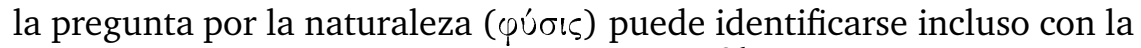
pregunta por la oủoí $\alpha$ de los entes naturales. ${ }^{26}$

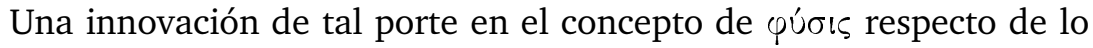
que se viene sosteniendo a lo largo de todo el segundo libro (es decir, una que pase de considerarla una causa inmanente o interna a considerarla una causa externa), resulta, por lo menos, poco plausible; más aún cuando ella no es anunciada de modo explícito, claro y directo. Que Aristóteles continúa aquí con la línea general del libro II de la Física puede suponerse, al menos con plausibilidad, del hecho de que centra su discusión de Fís. II 8 y 9 alrededor del problema de las causas

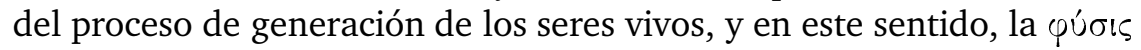
como "aquello con vistas a lo cual" es presentada como una causa operante en dichos procesos. Es preciso no perder de vista, además, este último punto: que a lo largo de Fís. II Aristóteles trata coherentemente la yúors como una causa, y volveremos a ello más adelante.

2. Mi segundo argumento apunta al alcance de la finalidad que es posible adscribir, si acaso, a la lluvia. Concedamos, pues, que llueve con vistas a un fin. Aun así no sería en absoluto claro que el fin en cuestión sea el crecimiento del grano. Puede interpretarse, cuando mucho, que Aristóteles insinúa que llueve con vistas a algo en 199a1-5 (o bien que ello se sigue de sus afirmaciones), pero sin especificar claramente con vistas a qué. Este punto no es menor, pues del hecho de que la lluvia sea con vistas a algo no se sigue necesariamente la vigencia de una teleología interactiva del tipo propuesto por Sedley y Furley, tal que un proceso meteorológico como la lluvia pudiera tener por fin el beneficio de otra sustancia. En efecto, el fin de la lluvia podría ser perfectamente intrínseco al proceso circular en que consiste la lluvia misma, ${ }^{27}$ que no es sino un epifenómeno de, o un evento asociado con, un caso de transformación elemental cíclica. En tal caso, se trataría de un caso de la llamada "teleología elemental"; pero es discutible que la vigencia de este tipo de teleología implique, además, que estas transformaciones ocurran con vistas al beneficio de otras sustancias naturales. ${ }^{28}$

${ }^{26}$ Cfr. Wagner 1995, p. 449; Weiss 1942, pp. 51 y 73, y de modo más extenso Rossi inédito.

${ }^{27}$ Cfr. Sobre la generación y la corrupción II 10, 337a1-15.

${ }^{28}$ Cfr. Matthen 2001; Johnson 2005, p. 141. Parte de la literatura secundaria, 
Con similares reservas puede interpretarse otro de los pasajes que suele invocarse como apoyo a la postura según la cual Aristóteles sostiene la vigencia de una teleología intersustancial del tipo mencionado. Se trata de Metafísica $\Lambda$ 10, 1075a11-25:

[1] Debemos considerar también en qué modo la naturaleza de la totalidad posee el bien y lo mejor: si como algo separado y 〈existente〉 por sí mismo, o como el orden. [2] ¿O es en ambos modos, como en un ejército? Pues el bien de un ejército está en su orden y también en el general. $\mathrm{Y}$ en mayor medida en el general, dado que él no es causado por el orden, sino que el orden es causado por él. [3] Todas las cosas - tanto las criaturas que nadan, como las que vuelan y las plantas- están ordenadas conjuntamente de cierto modo, pero no de la misma manera. [4] Y 〈el orden〉 no es tal que una cosa no tiene relación con otra, sino que tienen cierta relación. En efecto, todas las cosas están ordenadas conjuntamente en relación con una única cosa. [5] Pero es como en una familia, donde los libres tienen menos licencia para hacer lo que sea, y todo o la mayor parte de lo que hacen está ordenado, mientras que los esclavos y los animales hacen poco en pos de lo común, y la mayoría de las veces hacen lo que sea. [6] Pues ésta es la clase de principio que, de cada uno de ellos, es la naturaleza. [7] Quiero decir, por ejemplo, que al menos todos ellos necesariamente terminan por destruirse; y del mismo modo hay otras maneras en que todas las cosas contribuyen a la totalidad. ${ }^{29}$

Si bien no puedo detenerme en la discusión de este pasaje con la extensión que merecería, por una cuestión de espacio, ${ }^{30}$ vale la pena dedicar

en efecto, considera que la explicación teleológica del movimiento de los cuerpos simples no se identifica con la explicación teleológica de los seres vivos compuestos a partir de ellos; por mi parte, tiendo a estar de acuerdo con quienes entienden que ésta es la opinión de Aristóteles (véase, por ejemplo, el texto de Meteorológicos IV 12, 390b2-14). Dicho de otro modo: los cuerpos simples y su capacidad de combinarse y ser afectados, si bien son con vistas a algo, no son con vistas al ser vivo; Cooper 1987, pp. 261-262; cfr. Johnson 2005, pp. 143-144, Scharle 2008 y supra nota 11. En este registro, el caso del proceso circular de la lluvia y su relación con el crecimiento del grano no sería diferente del caso de la materia elemental y su relación con los seres vivos.

${ }^{29}$ En los puntos fundamentales sigo la traducción del texto al inglés propuesta por D. Sedley (2000) y su división del mismo para facilitar la discusión. Respecto

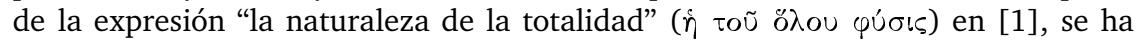
sugerido que puede entenderse de modo deflacionario como una forma de referirse simplemente al todo. A partir de [6], no obstante, Sedley argumenta convincentemente que hay que tomar en serio aquí la referencia a una naturaleza del todo, y que ella no sería sino el primer motor inmóvil (cfr. Sedley 2000, pp. 329-330).

${ }^{30}$ A ello se agrega que otros autores han dado ya argumentos muy convincen- 
algunas páginas a su análisis, dado que Sedley procura hallar en este texto el principio teleológico cósmico consistente en la naturaleza del universo (o de la totalidad), la cual operaría en el contexto de la discusión de Fís. II 8, según su interpretación, y daría cuenta del hecho de que la lluvia sea con vistas al crecimiento del grano. ${ }^{31}$

Por cierto, hay que decir que es al menos cuestionable importar sin más los resultados de una discusión de tipo teológico al contexto de Fís. II 8. Pero dejemos estos reparos iniciales de lado para considerar si a partir del texto de Metafísica $\Lambda 10$ puede sostenerse que la naturaleza del cosmos permitiría dar cuenta del pasaje de Fís. II 8 del modo en que Sedley lo entiende. Para sostener esto último, debería ser posible mostrar que el ordenamiento conjunto de los seres sublunares y la interacción sustancial a la que se alude en el pasaje de $\Lambda 10$ es tal que, en la jerarquía natural, las sustancias o procesos inferiores son (o pueden ser) con vistas a los superiores en el sentido de tener su fin en ellos y de ser con vistas al beneficio de ellos. Ahora bien, en este pasaje de la Metafísica, en el que se especifica cómo el primer motor ejerce una influencia causal a lo largo de la jerarquía cósmica, no parece haber

tes en contra de la lectura que Sedley realiza del texto. Me refiero en especial a M. Scharle (2008), a cuyo artículo remito para una discusión más extensa de este punto.

${ }^{31} \mathrm{D}$. Sedley sostiene, en efecto, que la naturaleza que él adscribe a la lluvia que beneficia al agricultor no es la naturaleza de la lluvia, pues el agua es un cuerpo elemental simple y no puede tener un principio interno del movimiento más allá de su tendencia a moverse hacia su propio lugar natural. De modo tal que la naturaleza en cuestión -que se muestra en la jerarquía natural antropocéntrica- debe ser no la naturaleza individual sino la global: la naturaleza del ecosistema entero (Sedley 1991, p. 192, 195; cfr. Sedley 2000, pp. 328-329, 331). Es la presencia de esta segunda naturaleza en el texto, claro, lo que está precisamente en discusión. Recientemente, M. Matthen ha defendido que la teleología operante en este tipo de fenómenos de transformación elemental sería holística, pero de tipo diferente del de la propuesta por Sedley. Matthen entiende que se trata de una teleología "interna" pero no por responder a la naturaleza del agua, sino a la naturaleza del universo como sustancia compuesta. El tipo de unidad que tendría esta sustancia compuesta (cuya materia serían los cinco elementos y cuya forma sería el primer motor inmóvil), según el propio Matthen, sería menos cohesiva que la de los organismos vivos que - como sabemos- constituyen los casos privilegiados de sustancias para Aristóteles. Si esto es así, deberíamos concluir que el universo mismo como sustancia "no es tan sustancia" como un ser vivo, o no lo es en el mismo sentido, algo que el propio autor reconoce en parte, pero cuyas consecuencias sistemáticas no desarrolla en profundidad. Tampoco está claro qué papel desempeñan los seres vivos en esta suerte de sustancia compuesta que sería el universo, según el autor.

Diánoia, vol. LV, no. 65 (Noviembre 2010). 
nada que apoye una interpretación del ordenamiento intersustancial de tal tipo. Veamos brevemente esto.

Tal como afirma Sedley, Aristóteles asigna aquí a la naturaleza

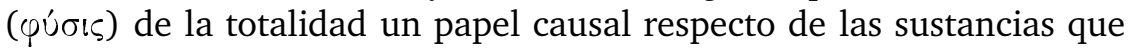
componen este orden cósmico, lo cual parece, en efecto, seguirse de [1] y de [6]. Este papel causal, según se sigue del texto, estaría expresado por el hecho de que [4] todas las sustancias están ordenadas con-

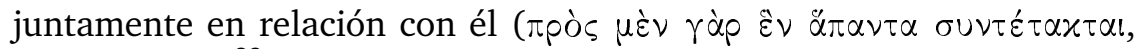
1075a18-19). ${ }^{32}$ Ahora bien, según el propio Sedley, esta influencia del primer motor, a lo largo de toda la cadena jerárquica, se produce en la medida en que las diferentes entidades aspiran a participar en lo divino tanto como pueden, y cada una del modo y en la medida en que puede. ${ }^{33}$ En efecto, los cuerpos celestes moviéndose en círculo imitan la actividad perfecta del primer motor, los seres vivos lo hacen por vía de la reproducción, ${ }^{34}$ y los elementos imitan el movimiento circular eterno del sol. ${ }^{35}$ En este último caso, pues, puede explicarse perfectamente el fenómeno de la lluvia: se trata de un proceso de transformación mediante el cual el agua imita el movimiento eterno del sol, y así indirectamente al primer motor. ${ }^{36}$ Esta relación de imitación indirecta, en la que una sustancia imita a otra que está más arriba en la jerarquía, da cuenta, precisamente, de la organización teleológica conjunta a la que alude el pasaje.

Dado que [2] el bien del todo, asociado a su naturaleza, está principalmente en el primer motor, pero al mismo tiempo atraviesa toda la jerarquía cósmica en cuanto que ella se encuentra ordenada en función de aquél, el punto es entonces si estas cosas son con vistas al primer motor (o dado el caso, a las sustancias superiores en la jerarquía) no sólo por ser éste su meta, sino además por ser su beneficiario (i.e., en ambos sentidos de "con vistas a algo"), lo cual apoyaría la lectura según la cual se trata de una cadena jerárquica en que los eslabones inferiores son con vistas al beneficio de los superiores (y así, la lluvia sería con vistas al crecimiento del grano). En contra de esta última lectura, hay

${ }^{32}$ Sedley 2000, pp. 332-333. En esta medida, puede entenderse el papel causal del primer motor como el de una causa final; para una buena discusión de este punto, en el que no puedo detenerme, véase J.A. Ross 2007, pp. 190-219.

${ }^{33}$ Sedley 2000, p. 333.

${ }^{34}$ Cfr. Sobre el alma II 4, 415a26-b7; Sobre la generación de los animales II 1, 731b24-35.

${ }^{35}$ Cfr. Sobre la generación y la corrupción II 10, 337a1-7.

${ }^{36}$ Para la lectura según la cual la teleología en juego en Fís. II 8 sería exclusivamente la teleología elemental, véase Scharle 2008. 
que decir que, como señala M. Scharle, en tres de los cinco pasajes en que Aristóteles introduce la distinción entre estos dos sentidos de "con vistas a algo" lo hace precisamente para subrayar que las sustancias individuales están orientadas teleológicamente hacia el primer motor como su meta, pero no como su beneficiario. ${ }^{37}$ Así, los individuos aspiran al primer motor, pero no para beneficiarlo, sino para mejorar su propia condición aproximándose, en la medida en que es posible para

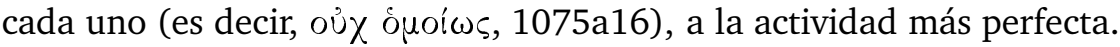

En este punto estoy de acuerdo, nuevamente, con M. Scharle: en definitiva, no parece haber en Metafísica $\Lambda 10$ evidencia de que el ordenamiento jerárquico que allí se propone sea tal que las sustancias inferiores son con vistas al beneficio de las superiores. El texto no ofrece ninguna indicación que apoye tal lectura. ¿Cómo daría cuenta entonces Aristóteles de este tipo de interacciones sustanciales, si no es por recurso a la naturaleza del todo? Yendo a los tratados biológicos, encontramos que la forma en que Aristóteles explica las relaciones intersustanciales en las cuales una sustancia obtiene un beneficio de otra se apoya siempre en la naturaleza del beneficiario, y no en una naturaleza cósmica, ni en la naturaleza de la sustancia que beneficia a la otra. ${ }^{38}$ Esto es: si la planta es, por ejemplo, con vistas al beneficio de un animal herbívoro, es porque es parte de la naturaleza del animal el obtener beneficio de esas plantas; de modo correspondiente, habría que pensar, si la lluvia es con vistas al crecimiento del grano, ello encuentra su explicación en la naturaleza del grano y no en la de la lluvia, o mejor, del agua. ${ }^{39}$

En definitiva, del hecho de que las naturalezas sublunares estén ordenadas conjuntamente con vistas a un único principio, que sería la naturaleza del todo, no se sigue que el fin de la lluvia sea el crecimiento del grano (y eventualmente del grano sembrado), sino, cuando mucho, que estamos ante un caso de teleología elemental, es decir, que el proceso de la lluvia sería con vistas a imitar —en la medida en que

${ }^{37}$ Scharle 2008, p. 158; los tres pasajes en cuestión son: Metafísica $\Lambda$ 7, 1072b13, Ética Eudemia VIII 3, 1249b13-16, y Sobre el alma II 4, 415b1-3.

${ }^{38}$ Éste es un punto de fundamental importancia que han señalado tanto Judson 2005 como Scharle 2008.

${ }^{39}$ Por mencionar algunos ejemplos: el camello tiene la lengua carnosa y varios estómagos porque la comida de la que se alimenta es espinosa, leñosa y difícil de digerir, y no a la inversa (Sobre las partes de los animales III 14, 674a29-b5); las aves marinas tienen un alimento húmedo y fácil de triturar, y por ello su estómago es húmedo y tienen un gran buche (ibid. III 14, 674b30-34); la forma del pico, la longitud del cuello y las patas de diferentes aves se explican también en función del lugar y el modo en que obtienen su alimento (ibid. IV 12, 692b20-693a23).

Diánoia, vol. LV, no. 65 (Noviembre 2010). 
es posible para los cuerpos simples- el movimiento circular del sol y con ello, indirectamente, la actividad del primer motor inmóvil.

3. Mi tercer argumento procede de modo indirecto. Si damos por verdadera la interpretación según la cual Aristóteles defiende aquí la tesis de que llueve con vistas a que el grano crezca, surgen una serie de problemas no menores.

En primer lugar, y sin tener en vista la tesis de la teleología antropocéntrica defendida por Sedley, sino una tesis más general del tipo de la que sostiene Furley, habría que decir lo siguiente: siendo que la lluvia constituye algo beneficioso para una gran cantidad de seres vivos, es decir, si ha de buscarse un fin de la lluvia que sea extrínseco a la misma, ¿por qué habría de ser ella con vistas al crecimiento de las plantas, antes que con vistas a saciar la sed de los animales terrestres (incluyendo el ganado), e incluso con vistas al beneficio de la mayoría de los peces? ¿Y por qué habría de ser con vistas al beneficio de todos ellos y no al perjuicio de las aves y de ciertos peces? ${ }^{40}$

Parece haber, pues, una multiplicidad de fines, incluso contradictorios, para un mismo proceso: la lluvia. Si ello es así, difícilmente puede defenderse que todos esos resultados que se verifican al llover son además, y al mismo tiempo, causas finales de la lluvia. ${ }^{41}$ En efecto, si quisiéramos sostener que todos los resultados que produce la lluvia son sus causas finales, tendríamos una multiplicidad de causas del mismo tipo (sc., final) para una misma cosa, lo cual implicaría que todas ellas excepto una deben ser accidentales, es decir, concomitantes respecto de una causa final que sería per se. De hecho, el caso de la lluvia así entendido exhibe un notable paralelismo estructural con uno de los ejemplos de ser por accidente que ofrece Aristóteles en Metafísica E 2:

${ }^{40}$ Investigación sobre los animales VIII 18, 601a26 ss.; VIII 19, 601b32-602a3. Por el contrario, y de modo acorde con lo señalado en el punto anterior, Aristóteles no explica los fenómenos climáticos estacionales en función de la naturaleza de los seres vivos, sino que más bien explica ciertas conductas de los seres vivos en función de las variaciones climáticas estacionales. Es el caso de las conductas migratorias en invierno (cfr. Investigación sobre los animales VIII 12, 596b20-28), por citar un ejemplo.

${ }^{41}$ Se daría en este caso un modo de operar de la causa final que, curiosamente, resultaría inverso al que se verifica en el caso de los organismos individuales. En el desarrollo de estos últimos, una multiplicidad de potencialidades pertenecientes a la materia confluye en la unidad de un fin (causa) consistente en la potencialidad de la forma de ese organismo. En el caso de la lluvia o de otros fenómenos climáticos, en cambio, una única potencialidad perteneciente a la materia se ramificaría en una multitud de "causas finales". 
ninguna ciencia, ni práctica ni productiva, ni teórica, se ocupa de aquél [sc., del ser por accidente]. En efecto, quien hace una casa no hace las

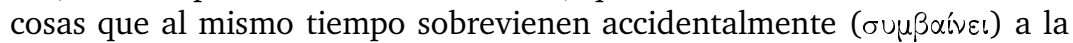
casa ya hecha (estas cosas en efecto son infinitas, pues nada impide que la casa, una vez terminada, sea agradable para unos, peligrosa para otros, y provechosa para otros [...]: la ciencia productiva que se ocupa de construir casas $\langle$, pues, $\rangle$ no versa sobre ninguna de estas cosas. (1026b4-10)

Naturalmente, la casa en cuestión es beneficiosa para unos y peligrosa para otros (y cada uno de los individuos involucrados podría dar razones por las cuales esto no resulta caprichoso respecto de ellos mismos, del mismo modo que, considerado desde el punto de vista de la planta, no es accidental su crecimiento a partir de recibir el agua de la lluvia); el punto es, más bien, que este beneficio y este perjuicio no han sido la causa de que la casa se produjera del modo en que se ha producido, y de ello da cuenta el hecho de que el constructor no tenga por objeto aquellas consecuencias concomitantes al construir la casa, sino sólo la esencia de "casa", que es la causa final per se, y que él posee en la medida en que posee el arte de construir casas. ${ }^{42}$

En cuanto a lo que Aristóteles, según entiendo, estaría dispuesto a aceptar, es importante reiterar que, naturalmente, desde el punto de vista del proceso consistente en el crecimiento del grano, no podría decirse que es un accidente que aquél crezca gracias a que llueve, puesto que la lluvia (o mejor, el agua) forma parte del proceso de nutrición hipotéticamente necesario para que una planta crezca. El punto de Aristóteles debe ser, más bien, que el crecimiento del grano es accidental considerado con relación a las causas del proceso por el cual llueve, ${ }^{43}$ el cual es descrito precisamente en términos materiales (198b19-20). El contraargumento de Sedley 1991, p. 183, según el cual Aristóteles admite en el ámbito natural lo que suelen llamarse "explicaciones dobles", es decir, explicaciones materialistas y teleológicas para los mismos fenómenos o procesos o cosas (de modo tal que no necesariamente una de ellas excluye a la otra, ni la vuelve "accidental") es en parte atendible; pero hay que decir que las "explicaciones dobles", a las que hace mención el autor, se dan respecto de procesos como la respiración (Sobre las partes de los animales I 1, 642a32-b4), o respecto de partes del cuerpo como el cabello en los hombres (ibid. II 14, 658b2-10) y los

${ }^{42} \mathrm{D}$. Sedley reconoce expresamente que la lluvia no sirve a un solo fin, sino que el crecimiento del grano es meramente uno de los fines a los cuales sirve la lluvia (Sedley 1991, p. 185); pero aparentemente no encuentra en ello problema alguno.

${ }^{43}$ Del mismo modo entiende esto Johnson 2005, p. 152.

Diánoia, vol. LV, no. 65 (Noviembre 2010). 
cuernos en los ciervos (ibid. III 2, 663b12-664a8), esto es: procesos y cosas que tienen lugar "en el interior" de una entidad u organismo. En otras palabras, dentro de estas "explicaciones dobles" que ofrece Aristóteles, las explicaciones teleológicas apelan a una causalidad final intrínseca respecto de una entidad en la que tienen lugar los procesos "necesarios" a los que apela la explicación doble, y no a una causalidad final externa respecto de dicha entidad, como ocurriría con la lluvia según este autor. ${ }^{44}$ Por ello, no parece que dichos casos - y con ellos, la validez del esquema de las "explicaciones dobles" - sean analogables al caso de la lluvia que estamos analizando, a no ser que se cometa una petición de principio.

Finalmente, respecto de este tercer argumento, es evidente que puede formularse un ulterior argumento análogo en contra de la tesis específica de la teleología antropocéntrica, pues hay una cantidad de consecuencias beneficiosas y perjudiciales de la lluvia para diferentes actividades humanas. Me limito a mencionar esto sin desarrollar el argumento, pues creo que resultaría redundante.

4. Mi cuarto argumento vale específicamente contra la tesis según la cual Aristóteles presentaría en Fís. II 8 una teleología natural interactiva de tipo antropocéntrico, y se agrega a los anteriores, que tenían más amplio alcance.

El punto que quiero defender es que, aun cuando se admitiera una interpretación antropocéntrica de la teleología natural aristotélica, este tipo de teleología resultaría causalmente poco relevante en el contexto de Fís. II. Dicho de otra manera: el sentido en el cual puede interpretarse que el fin de la agricultura es aquello con vistas a lo cual llueve, no es (y no puede ser) el mismo sentido en que la Qúors es una causa como "aquello en vistas de lo cual las partes de los animales se generan".

La diferencia entre uno y otro caso deriva del hecho de que en el primer caso nos hallamos ante un principio o causa interno, y en el otro no. Aún más, la diferencia entre ambos tipos de fin refleja y retoma

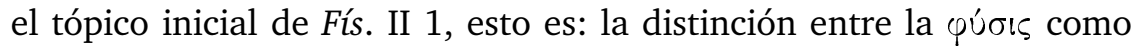
causa y principio interno del movimiento y la $\tau \varepsilon \dot{\chi} \chi \nu \eta$, que constituye un principio externo del movimiento (cfr. 192b12-23). Ambas, tanto la

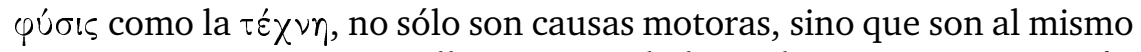
tiempo causas como "aquello en vistas de lo cual". Esta contraposición planteada por Aristóteles al comienzo del libro II resulta fundacional respecto de la discusión de las causas naturales que sigue a lo largo

${ }^{44}$ Cfr., en el mismo sentido, Sedley 2000, p. 334.

Diánoia, vol. LV, no. 65 (Noviembre 2010). 
de todo el libro: Aristóteles está demarcando aquí el ámbito ontológico que constituye el objeto de esta ciencia.

La diferencia entre una causa final interna y una externa no es meramente nominal, ni locativa. Un fin es una causa externa cuando se sirve de un proceso que se da con independencia de él mismo, de modo tal que el fin de dicho proceso, cuando es externo, no tiene un papel causalmente relevante respecto del proceso en cuestión. Por ejemplo, la condensación del agua ocurre con independencia del crecimiento de la planta, pues ella se produciría aunque no hubiera sembradíos; pero la producción del ojo a partir de determinado tipo de materia no se da con independencia de la esencia de este ser vivo, en el sentido fuerte de que la esencia del ser vivo es la causa de que el ojo se genere, y de que se genere de esta manera y a partir de este tipo de materia, tal que sea capaz de cumplir con la función que le es propia. En este contraste se ve la diferencia entre el peso causal de uno y otro sentido de "fin": en los casos en que la naturaleza es un fin como causa interna, ella es causa en el sentido fuerte de ser una condición necesaria para que se produzca lo causado por ella: si no se da la forma del ser vivo que es el lobo, como causa final, no hay ni ojo, ni colmillos, ni patas de lobo. ${ }^{45}$ El fin, en este sentido, es causa de la existencia de las cosas causadas por él, por ejemplo, de las partes de los animales. Por el contrario, la agricultura, o el crecimiento del grano sembrado, no son condición necesaria de que ocurra el proceso de la lluvia en este sentido. El propio Sedley debería aceptar esto, puesto que acepta que el crecimiento del grano es sólo un fin de la lluvia entre otros.

De aquí parece seguirse que el grano sembrado como aquello en vistas de lo cual llueve, o mejor, el hombre como aquello en vistas de lo cual crece el grano sembrado gracias a la lluvia, no puede considerarse un fin en un sentido causalmente relevante respecto del proceso natural del cual obtiene un beneficio.

En Fís. II 2 Aristóteles hace referencia precisamente a estos dos modos de entender el fin o "aquello con vistas a lo cual" a los que ya me he referido en mi segundo argumento: "en efecto, nosotros también somos un fin en cierto modo $[\pi \omega \varsigma]$, pues 'aquello con vistas a lo cual' se dice de en dos sentidos" (194a35-36); i.e., (i) como el beneficiario de un evento o proceso, y (ii) como el beneficiario de un proceso que es

${ }^{45}$ No hallamos, de hecho, cabezas, brazos y ojos separados pululando en la naturaleza, como quería Empédocles (Cfr. DK 31B57; cfr. DK 31A72 y Furley 1987, pp. 94-98), sino siempre como las partes de seres vivos determinados (cfr. Metafísica Z 10, 1035b23-31; Sobre las partes de los animales I 5, 645a30-36).

Diánoia, vol. LV, no. 65 (Noviembre 2010). 
además el fin intrínseco (i.e., como la causa final) de dicho proceso. ${ }^{46}$ En el sentido (i), en efecto, el agricultor, y en general el hombre, en cuanto destinatario último del alimento cosechado, es aquello en vistas de lo cual llueve, tal como afirma Sedley. El punto que resulta difícil de aceptar es, empero, que este segundo sentido de "con vistas a algo" tenga la relevancia causal que Sedley quiere adscribirle.

W. Kullmann, en su tratamiento de los diferentes sentidos de "aquello con vistas a lo cual" en Aristóteles, interpreta el sentido (i) de un modo tal que el beneficiario del proceso es un fin en sentido secundario respecto del proceso considerado en sí mismo. ${ }^{47}$ Kullmann identifica este tipo de relación entre proceso y fin secundario como el que se da entre los materiales que se hallan en la naturaleza y los fines de la técnica; es decir, precisamente en el tipo de caso que estamos considerando a propósito de la lluvia que cae sobre el sembradío. Y, a mi entender, esto no es en modo alguno arbitrario: Aristóteles mismo introduce esta

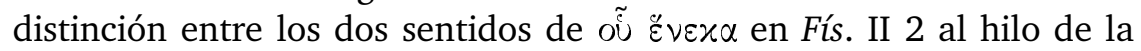
afirmación según la cual ciertas técnicas se sirven de la materia (la cual se halla dada en la naturaleza y posee sus propias potencialida-

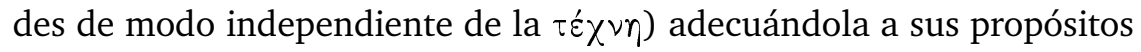
(cfr. 194a33-35). En la actividad técnica utilizamos o nos servimos de la materia que hallamos en la naturaleza como si estuviera allí para ser utilizada por nosotros; i.e., para nuestro beneficio. ${ }^{48}$ Pues nosotros también ( $(\alpha \alpha i)$ somos un fin en cierto modo $(\pi \omega \varsigma)$, agrega Aristóteles en seguida, aclarando que "aquello en vistas de lo cual" tiene dos sentidos. La formulación de esta afirmación inclina a pensar que precisamente el sentido en que nosotros somos un fin no es el mismo en que la naturaleza lo es: no sólo por la presencia del xaí adverbial, sino además por el adverbio de modo $\pi \omega \varsigma$ que parece matizar el juicio según el cual nosotros somos también un fin, en un contexto en que el tema central es la naturaleza como fin. De hecho, sigue de inmediato la aclaración

${ }^{46}$ Cfr. Sobre el alma II 4, 415b20-21.

${ }^{47}$ Kullmann 1985, p. 172.

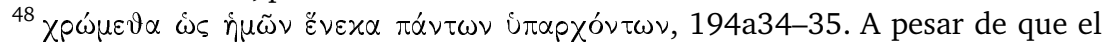
modo en que traduzco este pasaje es el más natural y extendido, Sedley (1991, p. 189) afirma que el $\grave{s}$ ante el genitivo absoluto no debe traducirse por "como si", sino con sentido causal. No obstante, LSJ (s.v., C.I.3) da el sentido "como" o "como si" para $\omega \varsigma$ con genitivo absoluto. Goodwin 1892, § 1574, da el sentido causal de $\omega s$ pero con el acusativo absoluto. Como quiera que sea, esto último expresa las razones subjetivas del agente para actuar, y no la causa en sentido objetivo (siempre siguiendo a Goodwin), de modo tal que tampoco sirve de fundamento para la lectura de Sedley.

Diánoia, vol. LV, no. 65 (Noviembre 2010). 
indispensable para hacer plausible esta afirmación: "aquello en vistas de lo cual" tiene dos sentidos.

Nosotros somos un fin en un sentido diferente del de la naturaleza. ${ }^{49}$ $Y$ no es descabellado pensar que la diferencia reside precisamente en el carácter intrínseco y extrínseco (respectivamente) del fin respecto del proceso cuyo resultado contribuye a dicho fin. Dicho de otro modo: la finalidad de la agricultura no es la causa del proceso de la lluvia a pesar de que la lluvia resulta (o suele resultar) beneficiosa para los fines de la agricultura. Esta finalidad de la agricultura resulta ser, por así decir, sobreimpuesta al proceso necesario, a partir de una actividad que se sirve del mismo, y de su regularidad, como medios. Este tipo de esquema es válido, al parecer, para todas las técnicas que operan sobre la base de ciertos procesos o hechos naturales que son necesarios desde el punto de vista material.

En efecto, la deliberación técnica, tal como se describe en Metafísica Z 7 (1032b5 ss.) apelando al caso de la medicina, se apoya en el conocimiento de este tipo de procesos materiales necesarios, retrotrayendo los efectos que se desea producir a sus causas hasta encontrar el punto en el cual intervenir activamente de modo que desencadene un proceso tal. Y un proceso tal lo desencadena el médico en vistas de un fin; v.gr., la salud. Pero que el calor se produzca en el cuerpo siempre que ocurre la ingesta de determinado alimento, por ejemplo, es algo necesario desde el punto de vista material; i.e., ello no es, en sí mismo, en vistas de la salud, sino que es meramente necesario. Es el médico el que utiliza esta necesidad material como medio en vistas de la salud, dado que el equilibrio corporal (en lo cual consiste la salud) necesita restaurarse en determinados casos por medio del calor. En el caso de la agricultura, cambiando lo que hay que cambiar, sucede lo mismo: la lluvia es un proceso necesario que ocurre siempre o la mayoría de las veces en determinado momento del año; el agricultor, pues, utiliza esta necesidad material como medio en vistas de que el grano crezca, dado que el grano necesita agua para crecer. Más aún, generalizando, es posible sostener incluso que el desarrollo de ciertas técnicas consiste, precisamente, en el descubrimiento de conexiones entre ciertas regularidades que se dan en la naturaleza con independencia de la intervención humana y ciertas consecuencias de dichos procesos regulares directa o indirectamente beneficiosas para el hombre; la técnica explota, por así decir, dicha conexión entre proceso-resultado beneficioso.

${ }^{49}$ Cfr. Berti 1989-1990, pp. 45-46, quien también entiende que este pasaje de Fís. II 2 habla en contra de una teleología antropocéntrica.

Diánoia, vol. LV, no. 65 (Noviembre 2010). 
D. Sedley admite que se podría formular una crítica similar a la que aquí propongo (es decir, una que apunte a las diferencias entre la técnica y la naturaleza) y, de hecho, entiendo que esta objeción es la más contundente desde el punto de vista conceptual contra la interpretación de Sedley. El autor, no obstante, se anticipa a esta crítica aduciendo que Aristóteles no hubiera sostenido que la agricultura surge del modo que he descrito, sino que lleva hasta las últimas instancias la analogía entre la teleología biológica y la cosmológico-antropocéntrica, reafirmando la ausencia de diferencias causales entre el fin en uno y otro caso: "Así como el funcionamiento teleológico de las partes del cuerpo constituye una interrelación simbiótica permanente, sin origen evolucionario, así también la relación armoniosa del hombre con su medio ambiente local es una característica inherente a un orden natural eterno"(Sedley 1991, pp. 186-187; la traducción es mía).

Por mi parte, creo que hay buenas razones para considerar que la afirmación de Sedley —que implica que para Aristóteles no sólo las especies como causas finales, sino también las técnicas como causas finales son ingeneradas, o al menos no tienen un origen evolucionarioes falsa. Muy brevemente: la técnica reconoce de hecho un origen "evolucionario" en opinión de Aristóteles. Esto es un punto de fundamental importancia, pues debilita una vez más la equiparación que pretende establecer Sedley entre ambos tipos de causa final. El pasaje más claro en este sentido es sin duda Refutaciones sofísticas 34, 183b17-184b8, donde Aristóteles se refiere al largo y paulatino proceso de colaboración intersubjetiva y diacrónica por el cual una técnica se desarrolla, se perfecciona y se completa a partir de un inicio usualmente imperfecto y tentativo, pero que por su carácter inaugural resulta de la mayor importancia. Si bien se trata en ese pasaje principalmente de técnicas de argumentación — v.gr. la dialéctica y la retórica-, Aristóteles se ocupa de aclarar que lo mismo vale, poco más, poco menos, "también respecto de todas las demás técnicas". ${ }^{50}$

\section{V}

5. Mi último argumento apela a ciertos aspectos más bien técnicos de la estructura argumentativa del pasaje en su conjunto, y se dirige contra el principal sustento textual de las lecturas de las que pretendo apartarme, esto es, el argumento (II) que ocupa el pasaje 198b36-199a5,

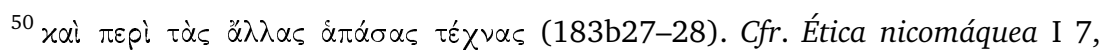
1098a22-26.

Diánoia, vol. LV, no. 65 (Noviembre 2010). 
donde Aristóteles afirma que la lluvia en cierto momento del año no se considera azarosa, y luego sostiene que si estas cosas no son por azar, entonces son con vistas a un fin. De donde - al parecer- se sigue que llueve con vistas a algo y, por lo tanto, que Aristóteles consideraba falso el primer término ( $a$ ) de la analogía en la dificultad inicial (I), es decir, que aquí se confirmaría que para Aristóteles sí llueve con vistas al crecimiento del grano en el sembradío.

Hay algunas razones para poner en duda que el ejemplo de la lluvia introducido en el argumento (II) deba ponerse en conexión lineal con el primer término de la analogía en la dificultad (I). La fundamental es, a mi entender, que el argumento (II) no constituye una resolución de la dificultad, sino un argumento independiente destinado a probar la falsedad de la conclusión del argumento inicial que constituye la dificultad. ${ }^{51}$ Recordemos la diferencia entre ambos procedimientos argumentativos. Una resolución ( $\lambda$ ú $\sigma ı)$ consiste en mostrar, o bien que la conclusión del argumento no se sigue de las premisas (es decir, que en realidad no se trata de un argumento), o bien que una o varias de las premisas son falsas. ${ }^{52}$ Y Aristóteles no parece dirigir su estrategia de manera evidente a ninguna de estas cosas en el argumento (II). Un argumento independiente, en cambio, no apunta a mostrar los defectos (materiales o formales) del argumento inicial, de modo tal que no se hace cargo de los puntos de partida de dicho argumento, sino que procede desde una nueva perspectiva, procurando concluir lo contrario que el argumento anterior. En tal sentido, podemos pensar que se trata de un contraargumento. ${ }^{53}$

El argumento (II) comienza, de hecho, con una referencia directa a la falsedad de la conclusión de (I): "Pero es imposible que sea de ese

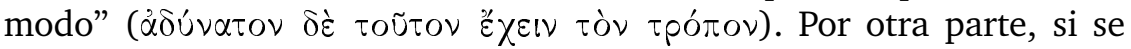
objetara que con el ejemplo de la lluvia Aristóteles está demostrando la falsedad de la tesis según la cual llueve por necesidad, habría que responder, en primer lugar, que el argumento (I) no queda resuelto mediante la mera declaración de la falsedad del primer término de la

${ }^{51}$ W. Charlton (1992, p. 123) también parece tratar este pasaje como un argumento independiente.

${ }^{52}$ Tópicos VIII 10, 160b23-37; Refutaciones sofísticas 18, 176b29-177a6.

${ }^{53}$ Este procedimiento argumentativo, en efecto, se acerca a lo que Aristóteles

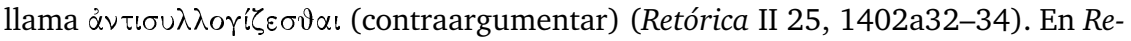

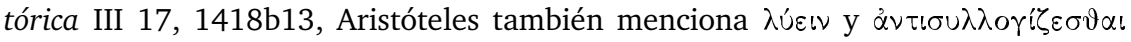
como dos actividades o maneras diferentes de oponerse a un argumento. Para la distinción entre ambos procedimientos argumentativos, véase también Refutaciones sofísticas $24,179 \mathrm{~b} 18-24$.

Diánoia, vol. LV, no. 65 (Noviembre 2010). 
analogía, lo cual no podía escapar a Aristóteles, y en segundo lugar, que Aristóteles no demuestra en (II) la falsedad de la tesis según la cual llueve por necesidad y no con vistas al crecimiento del grano, sino que el caso de la lluvia aparece en este segundo argumento mencionado como un ejemplo, destinado a ilustrar una premisa diferente. Veamos esto brevemente.

La tesis que procura refutar Aristóteles con el argumento (II) afirma que "allí donde todas las cosas resultan tal como si se hubieran generado en vistas de algo, éstas 〈en realidad〉 perduran por azar (ảંò

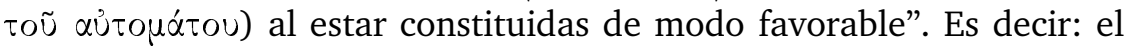
carácter favorable de las partes de los animales para el desempeño de ciertas funciones, e incluso en general para la supervivencia del ser vivo en cuestión, no es la causa de la generación de dichas partes, sino que sólo es causa del hecho de que el animal que las posee perdure o sobreviva, ${ }^{54}$ habiéndose generado ellas por otro tipo de causas; v.gr., materiales. En el argumento (II) Aristóteles intenta, pues, quitar plausibilidad a esta idea apelando a otra característica comúnmente asociada al azar, a saber: el carácter excepcional de lo causado por este tipo de causa por oposición a la regularidad de lo que ocurre por naturaleza.

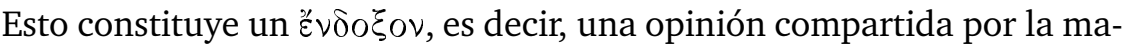

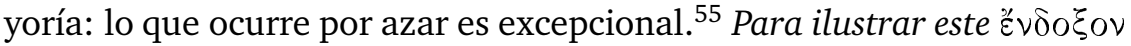
acerca del azar (y no la tesis acerca de la naturaleza), Aristóteles apela

${ }^{54}$ Vale aclarar, en este punto, que la concepción teleológica de Aristóteles no niega que el carácter favorable para el ser vivo de ciertas partes sea causa de la supervivencia del ser vivo. En efecto, las partes son en vistas del animal también en el sentido de que el ser vivo es el beneficiario de dichas partes, es decir, el ser vivo es "aquello en vistas de lo cual" en ambos sentidos distinguidos en Fís. II 2 (cfr. Kullmann 1985); eso es precisamente lo distintivo de la concepción teleológica de la naturaleza: el beneficio que comporta una cosa $x$ no sólo es resultado de la existencia de $x$, sino también causa de la existencia de $x$, en cuanto beneficio.

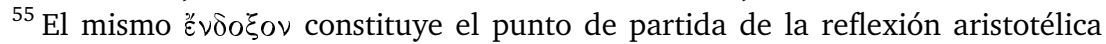
acerca del azar en Fís. II 5, 196b10-15. Como es evidente, hay una oscilación en el sentido de la noción de accidentalidad y de azar presentada como tesis rival de la teleología en las generaciones naturales en la aporía (I) y en el argumento (II). En el planteamiento de la dificultad (I), la accidentalidad se apoya en consideraciones de tipo causal en relación con un beneficio obtenido a partir de un proceso (i.e., a la ausencia de un propósito o causa final); y, en el argumento (II), se toma en cuenta el carácter excepcional de los fenómenos azarosos por contraposición a la regularidad de los fenómenos naturales. Esta oscilación puede interpretarse como una debilidad del argumento (II) sólo si se lo considera como una resolución de la dificultad inicial; si en cambio se trata de un contraargumento que pretende refutar la conclusión de la dificultad, la oscilación no constituye un problema fatal para el argumento. 
en (ii) al modo usual de referirse a determinado tipo de eventos climáticos según sean regulares o excepcionales en determinado momento del año. El quid de Aristóteles parece ser que nunca nos referiríamos mediante los términos "fortuito" o "azaroso" a ciertas cosas que coinciden usualmente: la lluvia-el invierno, el calor-el verano, sino que, por el contrario, llamamos azaroso a algo cuya coincidencia es poco usual: la lluvia-el verano, el calor-el invierno. El ejemplo puede entenderse, a mi juicio, como meramente instrumental; i.e., destinado a ilustrar la conexión entre lo azaroso y lo excepcional, o la diferencia entre lo azaroso y lo regular. Luego, en (iii), Aristóteles introduce la alternativa exhaustiva según la cual las cosas del tipo mencionado (v.gr., las partes de los animales y su generación, y en general las cosas que son por naturaleza) son o bien con vistas a algo o bien por coincidencia. El hecho de que esta alternativa se plantee como exhaustiva, también inclina a pensar que Aristóteles no está resolviendo la dificultad (I), sino que argumenta desde una nueva perspectiva. En efecto, en (I) aparecía de hecho un tercer elemento que rompería esta dicotomía: la necesidad, por la cual ocurre la lluvia.

En definitiva, el desarrollo del argumento (II) no basta, a mi juicio, para concluir que Aristóteles está defendiendo en él, indirectamente, la tesis según la cual llueve con vistas a que el grano sembrado crezca. El caso de la lluvia en invierno (así como el del calor en verano, que es presentado en pie de igualdad con el anterior) debe tomarse, creo, simplemente como un ejemplo destinado a ilustrar el hecho de que no diríamos que algo que no es excepcional ocurre por azar. ${ }^{56}$

\section{VI}

A partir de los argumentos que he propuesto, creo estar en condiciones de concluir que la discusión que Aristóteles lleva a cabo al comienzo de Fís. II 8 contra el materialismo no habría de contarse entre los textos que apoyan una lectura holística o de segundo orden de la teleología natural aristotélica y, en particular, que es muy poco plausible que Aristóteles esté defendiendo, o siquiera insinuando, en este texto, la tesis según la cual la teleología natural es antropocéntrica en un sentido causalmente relevante desde el punto de vista, justamente, natural.

La idea de que pudiera a atribuirse a Aristóteles la tesis de que la teleología natural es antropocéntrica resulta, no obstante, sostenible e

${ }^{56}$ Judson 2005, p. 349, también entiende que el caso de la lluvia en invierno y el calor en verano en el argumento (II) tiene sólo propósitos ilustrativos, si bien no ofrece para ello las razones que he expuesto aquí.

Diánoia, vol. LV, no. 65 (Noviembre 2010). 
interesante si se entiende esta tesis en un sentido instrumental o externo; es decir, en el otro sentido de "con vistas a algo": el hombre tiene la capacidad de subsumir o subordinar creativamente, con vistas a sus propios fines, las cosas y los procesos que se dan en la naturaleza con regularidad. En ello consistiría, poco más o menos, la invención y el desarrollo de las técnicas que se sirven de la materia (en sentido amplio) natural. Ahora bien, es cierto que estas técnicas no podrían desarrollarse si la materia no estuviera allí como para ser usada. El hecho de que Aristóteles reconozca que nosotros, es decir, los seres humanos, también somos un fin, parece hacer justicia así a la experiencia según la cual la naturaleza se nos aparece como una totalidad organizada (y cuya organización es posible conocer) tal que está ahí como para ser usada para nuestros fines. Ello por sí mismo no implica, no obstante, que las condiciones de posibilidad de este fenómeno estén dadas por la organización teleológico-antropocéntrica de la naturaleza misma. La otra posibilidad es que esas condiciones estén dadas más bien por el modo en que el ser humano accede a, o se dirige a, las regularidades que exhibe la naturaleza. Explorar hasta qué punto tal idea puede reconstruirse a partir de los textos de Aristóteles sería sin duda una tarea interesante, aunque no es posible acometerla aquí. Como sea, lo dicho no permite atribuir a Aristóteles la tesis según la cual los procesos naturales, teleológicamente orientados, están además direccionados intrínsecamente al cumplimiento de los fines que los seres humanos deciden darse a sí mismos y que se expresan subsidiariamente en los fines de las técnicas particulares. La lectura que intento defender tendría como resultado de largo alcance, en definitiva, rescatar la distinción y la discontinuidad a nivel causal-teleológico entre el orden práctico y el natural como algo propio de la filosofía aristotélica.*

*Quiero agradecer especialmente a mi maestro y amigo Alejandro Vigo, con quien he discutido en más de una oportunidad los problemas que me ocupan en este artículo, lo cual me ha permitido ajustar mi postura y afinar varios argumentos. Naturalmente, no quiero sugerir con esto que Alejandro suscriba mis puntos de vista sobre el asunto debatido. Va también mi sincero agradecimiento a los árbitros anónimos de Diánoia, cuyas observaciones me han permitido mejorar el texto en más de un punto. 


\section{BIBLIOGRAFÍA}

1. Aristóteles

Analíticos

posteriores

Ética eudemia

Ética

nicomáquea

Física

Investigación

sobre los animales

Metafísica

Meteorológicos

Política

Refutaciones

sofísticas

Retórica

Sobre el alma

Sobre el sueño y la vigilia

Sobre la generación de los animales

Sobre la generación y la corrupción

Sobre las partes de los animales

Tópicos
Aristotelis, Analytica Priora et Posteriora, ed. D.W. Ross, Oxford University Press, Oxford, 1964.

Aristotelis, Ethica Eudemia, ed. R. Walzer y J. Mingay, Oxford University Press, Oxford, 1991.

Aristotelis, Ethica Nicomachea, ed. I. Bywater, Oxford University Press, Oxford, 1894.

Aristotelis, Physica, ed. W.D. Ross, Clarendon, Oxford, 1956.

Aristote, Histoire des animaux, texto establecido y trad. P. Louis, Les Belles Lettres, París, 1964-1969; 3 vols.

Aristotelis, Metaphysica, ed. W. Jaeger, Clarendon, Oxford, 1957.

Aristote, Météorologiques, texto establecido y trad. P. Louis, Les Belles Lettres, París, 1982, 2 vols.

Aristotelis, Politica, ed. W.D. Ross, Clarendon, Oxford, 1957.

Aristotelis, Topica et Sophistici Elenchi, ed. D.W. Ross, Clarendon, Oxford, 1958.

Aristotelis, Ars Rhetorica, ed. D.W. Ross, Clarendon, Oxford, 1959.

Aristotle, De Anima, ed., introd. y comentarios de W.D. Ross, Clarendon, Oxford, 1999 (=1961).

En Aristotle, Parva Naturalia, texto revisado, introd. y comentarios de W.D. Ross, Clarendon, Oxford, 2001 (=1955).

Aristote, De la génération et de la corruption, texto establecido y trad. Ch. Mugler, Les Belles Lettres, París, 1966.

Aristotle, On Coming-to-be and Passing-away (De Generatione et Corruptione), texto revisado, introd. y comentarios de H. Joachim, clarendon, Oxford, 1999 (= 1926).

Aristote, Les Parties des Animaux, texto establecido y trad. P. Louis, Les Belles Lettres, París, 1956.

Aristotelis, Topica et Sophistici Elenchi, ed. D.W. Ross, Clarendon, Oxford, 1958. 


\section{Bibliografía secundaria}

Arnim, H. von, 1903-1905, Stoicorum veterum fragmenta, Teubner, Stuttgart, 1964 (= 1903-1905).

Balme, D., 1992, Aristotle, De Partibus Animalium I and De Generatione Animalium I (with passages from II 1-3), trad. y notas de D. Balme, con un informe sobre trabajos recientes y una bibliografía adicional de Allan Gotthelf, Oxford University Press, Oxford.

—_ 1987a, "Teleology and Necessity", en Lennox y Gotthelf 1987, pp. 275-285.

- 1987b, "Aristotle's Biology Was Not Essentialist", en Lennox y Gotthelf 1987, pp. 291-312.

Berti, E., 1989-1990, "La finalità in Aristotele", en Fondamenti, fasc. 14-15-16, pp. 8-44; reimpreso en Berti, Nuovi Studi Aristotelici II: Fisica, antropologia e metafisica, Morcelliana, Brescia, 2005, pp. 39-67. Se cita mediante la paginación de esta reimpresión.

Boeri, M.D., 1993, Aristóteles, Física. Libros I y II, trad., introd. y comentario de Marcelo D. Boeri, Biblos, Buenos Aires.

Broadie, S.W., 1982, Nature, Change and Agency in Aristotle's Physics, Oxford University Press, Oxford.

Charlton, W., 1992, Aristotle, Physics Books I and II, trad., introd. y comentario de W. Charlton, Oxford University Press, Oxford, 1995 (=1992).

Cooper, J., 1987, "Hypothetical Necessity and Natural Teleology", en Lennox y Gotthelf 1987, pp. 243-274.

_ 1982 , "Aristotle on Natural Teleology", en M. Schofield y Martha Nussbaum, Language and Logos, Cambridge University Press, Cambridge, 1982, pp. 197-222.

Diels, H., y Kranz, W., 1951, Die Fragmente der Vorsokratiker, 6a. ed., Weidmannsche Buchhandlung, Dublín/Zürich.

Furley, D., 1987, The Greek Cosmologists. Volume I: The Formation of the Atomic Theory and Its Earliest Critics, Cambridge University Press, Cambridge.

— 1985, "The Rainfall Example in Physics II 8", en Gotthelf 1985, pp. 177182.

Goodwin, W., 1892, A Greek Grammar, ed. revisada y aumentada, Ginn and Company, Boston.

Gotthelf, A. (comp.), 1987, "Aristotle's Conception of Final Causality", en Lennox y Gotthelf 1987, pp. 204-242.

_ 1985, Aristotle On Nature and Living Things, Mathesis Publications, Pittsburgh.

Hirsch, U., 1990, "War Demokritus Weltbild mechanistisch und antiteleologisch?", Phronesis, vol. 35, pp. 225-244.

Johansen, T.K., 2006, "Review of Monte Ransome Johnson, Aristotle on Teleology", Notre Dame Philosophical Reviews [en línea], disponible en <http:// ndpr.nd.edu/review.cfm?id=6883>, consultado el 22 de julio de 2009.

Johnson, M.R., 2005, Aristotle on Teleology, Oxford University Press, Oxford. 
Judson, L., 2005, "Aristotelian Teleology", Oxford Studies in Ancient Philosophy, vol. 29, pp. 341-366.

Kullmann, W., 1985, "Different Concepts of the Final Cause in Aristotle", en Gotthelf 1985, pp. 169-175.

Lennox, J. y A. Gotthelf (comps.), 1987, Philosophical Issues in Aristotle's Biology, Cambridge University Press, Cambridge.

Liddell, H., R. Scott y H. Jones, 1996, A Greek-English Lexicon, Oxford University Press, Oxford.

Long, A., y D. Sedley, 1987, The Hellenistic Philosophers, Cambridge University Press, Cambridge, 1989 (= 1987).

Mansion, A., 1946, Introduction a la Physique Aristotélicienne, Éditions de l'Institut Supérieur, Lovaina/París.

Matthen, M., 2001, "The Holistic Presuppositions of Aristotle's Cosmology", Oxford Studies in Ancient Philosophy, vol. 20, pp. 171-199.

Mayr, E., 1992, "The Idea of Teleology", Journal of the History of Ideas, vol. 53, pp. 117-135.

Nussbaum, M., 1978, Aristotle's De Motu Animalium, texto, trad., comentario y ensayos interpretativos de M. Nussbaum, Princeton University Press, Princeton.

Ross, J.A., 2007, Dios, eternidad y movimiento en Aristóteles, Editorial de la Universidad de Navarra, Navarra.

Ross, W.D., 1936, Aristotle's Physics, texto revisado con introd. y comentario de W.D. Ross, Oxford University Press, Oxford.

Rossi, G., 2006, "Desanudando argumentos: las aplicaciones filosóficas de la dialéctica según las Refutaciones sofísticas", Méthexis, vol. 19, pp. 79-109.

—_, inédito, El azar según Aristóteles. Estructuras de la causalidad accidental en los procesos naturales y en la acción racional, Academia Verlag, Sankt Augustin (Serie International Aristotle Studies) (en prensa).

Sauvé Meyer, S., 1992, "Aristotle, Teleology, and Reduction", Philosophical Review, vol. 101, pp. 791-825.

Scharle, M., 2008, "Elemental Teleology in Aristotle's Physics 2.8", Oxford Studies in Ancient Philosophy, vol. 34, pp. 147-183.

Sedley, D., 1991, "Is Aristotle's Teleology Anthropocentric?", Phronesis, vol. 36, pp. 179-196.

- 2000, "Metaphysics $\Lambda$ 10", en M. Frede y D. Charles, Aristotle's Metaphysics Lambda, Clarendon Press, Oxford, 2000, pp. 327-350.

Tomás de Aquino, 2006, Commentaria in octo libros Physicorum [en línea], Textum Leoninum Taurini 1954 editum ac automato translatum a Roberto Busa SJ in taenias magneticas denuo recognovit Enrique Alarcón atque instruxit, Fundación Tomás de Aquino, 2006, disponible en: < http://www.corpus thomisticum.org/cpy012.html\#71783>.

Wagner, A., 1995, Aristoteles, Physikvorlesung, 5a. ed. revisada, trad. A. Wagner, ed. H. Flashar, Akademie-Verlag, Berlín, vol. 11.

Wardy, R., 1993, "Aristotelian Rainfall or The Lore of Averages", Phronesis, vol. 38, pp. 18-30. 
Weiss, H., 1942, Kausalität und Zufall in der Philosophie des Aristoteles, Verlag Haus zum Falken, Basilea.

Wieland, W., 1970, Die aristotelische Physik, Vandenhoeck und Ruprecht, Gotinga.

Zeller, E., 1921, Die Philosophie der Griechen in ihrer geschichtlichen Entwicklung, zweiter Teil, zweite Abteilung, G. Olms, Hildesheim/Zürich/Nueva York, $1990=1921$.

Recibido el 22 de julio de 2009; aceptado el 3 de mayo de 2010. 